\title{
Baseline Sensitivity of Botrytis cinerea to Pyraclostrobin and Boscalid and Control of Anilinopyrimidine- and Benzimidazole-Resistant Strains by These Fungicides
}

\author{
C. K. Myresiotis, G. A. Bardas, and G. S. Karaoglanidis, Aristotelian University of Thessaloniki, Faculty of Agri- \\ culture, Plant Pathology Laboratory, POB 269, 54124, Thessaloniki, Greece
}

\begin{abstract}
Myresiotis, C. K., Bardas, G. A., and Karaoglanidis, G. S. 2008. Baseline sensitivity of Botrytis cinerea to pyraclostrobin and boscalid and control of anilinopyrimidine- and benzimidazoleresistant strains by these fungicides. Plant Dis. 92:1427-1431.

Fifty-five isolates of Botrytis cinerea collected from vegetable crops were used to determine the pathogen's baseline sensitivity to two new fungicides: boscalid, which inhibits the enzyme succinate dehydrogenase in the electron transport chain, and pyraclostrobin, which blocks electron transport between cytochrome $b$ and cytochrome $c_{1}$. Measurement of sensitivity to boscalid was based on both inhibition of mycelial growth and spore germination, while measurement of sensitivity to pyraclostrobin was based only on inhibition of spore germination. For both fungicides, the sensitivity distribution was a unimodal curve, with a mean $\mathrm{EC}_{50}$ value (effective concentration that reduces mycelial growth or spore germination by 50\%) of $0.033 \mu \mathrm{g} \mathrm{ml}^{-1}$ for pyraclostrobin and 2.09 and $2.14 \mu \mathrm{g} \mathrm{ml}^{-1}$ for boscalid based on the inhibition of mycelial growth and spore germination, respectively. No cross-sensitivity relationship was observed between the two fungicides $(r=0.09)$. In addition, no cross-resistance relationship was observed between these two fungicides with other botryticides: cyprodinil, pyrimethanil, fenhexamid, fludioxonil, and iprodione. Moreover, the control efficacy of the two fungicides was tested against two anilinopyrimidine-resistant and two benzimidazole-resistant isolates, and two of wild-type sensitivity. Both pyraclostrobin and boscalid provided satisfactory control of all six isolates that was independent of the isolate sensitivity to benzimidazoles and anilinopyrimidines. In contrast, carbendazim failed to control sufficiently the benzimidazole-resistant isolates, while cyprodinil failed to provide satisfactory control of the anilinopyrimidine-resistant isolates.
\end{abstract}

Additional keywords: fungicide resistance, gray mold

Gray mold, caused by Botrytis cinerea Pers:Fr., is a severe disease causing significant yield losses in vegetable crops such as tomato, eggplant, pepper, and cucumber in greenhouses throughout the Mediterranean basin. Since resistant varieties do not exist for these crops, control of the disease relies mostly on fungicide sprays. Growers around the Mediterranean basin apply fungicides on a calendar schedule, starting the applications in late October and ending them in late February to early March at 7- to 10-day intervals.

The fungicides used against gray mold belong to several classes. Until the mid1990 s, control of the disease was mainly achieved by applications of site-specific fungicides belonging to the benzimidazole, dicarboximide, and $N$-phenylcarbamate groups, while multisite inhibitors such as chlorothalonil, dichlofluanid, iminactodine, and captan were used in tank mixtures or in rotation with site-specific in-

Corresponding author: G. S. Karaoglanidis

E-mail: gkarao@agro.auth.gr

Accepted for publication 10 June 2008.

doi:10.1094/PDIS-92-10-1427

(C) 2008 The American Phytopathological Society hibitors (7). In the recent past, new botryticides possessing new mechanisms of action were developed and registered for use against gray mold worldwide. These new botryticides were the anilinopyrimidines, pyrimethanil and cyprodinil, the phenylpyrrole derivative, fludioxonil, and the hydroxyanilide derivative, fenhexamid (26). However, intensive use of these sitespecific inhibitors has led to a rapid selection of pathogen strains resistant to benzimidazoles, dicarboximides, and anilinopyrimidines in many countries worldwide $(4,8,9,15,19-21,23)$. In these cases, the introduction into spray programs of new fungicides belonging to different chemical groups with no cross-resistance with botryticides already in use could aid in overcoming limitations in disease control caused by fungicide resistance. Two new active ingredients, pyraclostrobin and boscalid, could play such a role.

Pyraclostrobin is among the newer members of the group of Quinone outside inhibitors (QoIs), a fungicide class that was developed from natural fungicidal derivatives such as strobilurin $\mathrm{A}$ and oudemansin A $(1,5)$. The mechanism of action of this fungicide class is the inhibition of mitochondrial respiration by binding at the Qo site of the cytochrome $b$, causing the blocking of electron transport between cytochrome $b$ and cytochrome $c_{1}$. Inhibition of mitochondrial respiration leads to a disruption of the energy cycle (5). Pyraclostrobin possesses an extremely broad spectrum of activity, including fungal species such as $B$. cinerea and oomycetes $(1,13,17)$.

Boscalid is a new broad-spectrum fungicide belonging to the carboxamide (anilide) class of fungicides. These fungicides possess a different mode of action, the inhibition of the enzyme succinate ubiquinone reductase, also known as succinate dehydrogenase (SDH) (6). The enzyme plays a crucial role in the tricarboxylic cycle and the mitochondrial transport chain, and its inhibition leads to a block of the cell energy cycle. Boscalid is active against several ascomycetous fungal species attacking fruit, vegetables, and vines, including $B$. cinerea $(18,29)$.

These two new fungicides, with modes of action distinct from those of botryticides already in use, could play a significant role in the control of the disease and in the management of resistance developed to other fungicide classes. However, it is well known that $B$. cinerea represents a classical high-risk pathogen for fungicide resistance development due to its high genetic variability, the abundance of sporulation, the short generation time, and the wide host range. Moreover, recent studies indicated a high risk for resistance development in this pathogen to pyraclostrobin (17) and a moderate risk for resistance development to boscalid (32). Consequently, the current study was conducted: (i) to determine the baseline sensitivity of $B$. cinerea isolates obtained from vegetable crops in Greece to these two fungicides, (ii) to determine the cross-sensitivity/ resistance patterns between boscalid and pyraclostrobin and with active ingredients from several other chemical classes, and (iii) to test the efficacy of pyraclostrobin and boscalid in controlling benzimidazoleand anilinopyrimidine-resistant strains of B. cinerea.

\section{MATERIALS AND METHODS}

Pathogen isolates. The $B$. cinerea isolates used in the current study were isolated from diseased vegetable crops grown in greenhouses on the Crete island, Greece, during the winter period of 2005 . The isolates were collected during a monitoring program to determine the sensitivity of pathogen isolates to several fungicides. 
Details on the isolation procedure and the determination of sensitivity to these fungicides have previously been described (21). The isolates were stored on potato dextrose agar (PDA) slants at $4^{\circ} \mathrm{C}$ until use. In total, 55 pathogen isolates were used.

Baseline sensitivity to pyraclostrobin and boscalid. Pure technical grades of the fungicides, provided by the manufacturer BASF Hellas (Athens, Greece), were used. The pure technical grades of these two fungicides were dissolved in pure acetone and ethanol, respectively, to prepare stock solutions.

For the measurement of sensitivity to pyraclostrobin, based on the inhibition of spore germination, autoclaved $2 \%$ water agar medium (Oxoid, Unipath Ltd., Basingstoke, England) was amended with $0.001,0.005,0.01,0.05$, and $0.1 \mu \mathrm{g} \mathrm{ml}^{-1}$ pyraclostrobin, as well as salihydroxamic acid (SHAM) in methanol at $100 \mu \mathrm{g} \mathrm{ml}^{-1}$. Control plates were amended only with acetone and methanol. The concentration of the solvents did not exceed $0.1 \%$ by volume in fungicide-amended and nonamended media.

For the measurement of sensitivity to boscalid that was carried out based both on inhibition of spore germination and mycelial growth, the growth media were amended with $0.05,0.1,0.5,1$, and $5 \mu \mathrm{g}$ $\mathrm{ml}^{-1}$ boscalid. Control plates were amended with ethanol at a concentration of $0.1 \%$ by volume. For the measurement of sensitivity based on inhibition of spore germination, the growth medium used was $2 \%$ water agar, while for the measurement based on inhibition of mycelial growth, a minimal medium was prepared containing $10 \mathrm{~g}$ glucose, $1.5 \mathrm{~g} \mathrm{~K}_{2} \mathrm{HPO}_{4}, 2 \mathrm{~g} \mathrm{KH}_{2} \mathrm{PO}_{4}$, $1 \mathrm{~g}\left(\mathrm{NH}_{4}\right) \mathrm{SO}_{4}, 0.5 \mathrm{~g} \mathrm{MgSO}_{4} \cdot 7 \mathrm{H}_{2} \mathrm{O}, 2 \mathrm{~g}$ yeast extract, and $12.5 \mathrm{~g}$ agar per liter. Tests for each isolate were replicated three times per concentration of each fungicide.

For the measurement of sensitivity based on inhibition of spore germination, conidia of each isolate from 10- to 12-day cultures grown on PDA were used to prepare suspensions containing $1 \times 10^{3} \mathrm{co}-$ nidia $\mathrm{ml}^{-1}$. Aliquots of the conidial suspension were spread on $6-\mathrm{cm}$ petri dishes containing the fungicides. After $12 \mathrm{~h}$ of incubation at $20^{\circ} \mathrm{C}$, the number of germinated conidia was measured. A conidium was considered germinated if the germ tube was at least half the length of the conidium. In total, 100 conidia were scored per petri dish, and there were three petri dishes per isolate and fungicide concentration.

For the measurement of sensitivity based on inhibition of mycelial growth, mycelial plugs were removed with the aid of a 5-mm cork borer from the margins of actively growing, 72-h-old colonies and placed upside down on the centers of $9-\mathrm{cm}$ plastic petri dishes containing the fungicide-amended or unamended media. Cultures were incubated at $20^{\circ} \mathrm{C}$ in the dark for 3 days, and then mean colony diameters were measured. Colony diameters on a fungicide-amended medium were expressed as percentage of the mean diameter on the unamended medium.

Control of anilinopyrimidine- and benzimidazole-resistant strains. Six $B$. cinerea isolates-two benzimidazoleresistant, two anilinopyrimidine-resistant, and two of wild-type sensitivity-were selected for the experiment carried out to determine the efficacy of pyraclostrobin and boscalid in controlling benzimidazoleand anilinopyrimidine-resistant strains of the pathogen. The isolates had been collected for the requirements of a monitoring program to determine the sensitivity of pathogen isolates to several fungicides (21). Details on the sensitivity of each of the six isolates to carbendazim, cyprodinil, pyraclostrobin, and boscalid are given in Table 1.

Cucumber seedlings (cv. Cetriolo Telegrafo) were grown in plastic pots $(18 \mathrm{~cm}$ diameter) containing a 2:1 mixture of peat and perlite. After sowing, pots were kept in the growth chamber at $23^{\circ} \mathrm{C}$. After appearance of the cotyledons, plants were treated with the fungicides, and $24 \mathrm{~h}$ later, they were inoculated with the six selected isolates.

Formulations of boscalid (F510 50WG) and pyraclostrobin (F500, 25EC) were provided by the manufacturer (BASF Hellas, Athens, Greece). In addition, applications of commercial formulations of cyprodinil (Chorus 50 WG, Syngenta Hellas, Athens, Greece) and carbendazim (carbendazim 50WP, Papaoikonomou Agrochemicals SA, Thessaloniki, Greece) were included in the study as reference treatments. Carbendazim was applied at a concentration of $100 \mu \mathrm{g} \mathrm{ml}^{-1}$, cyprodinil at 50 and $100 \mu \mathrm{g} \mathrm{ml}^{-1}$, and boscalid and pyraclostrobin at 25,50 , and $100 \mu \mathrm{g} \mathrm{ml}^{-1}$. The fungicides were applied to runoff with a hand-sprayer $24 \mathrm{~h}$ before inoculation of the cucumber seedlings. Control plants were sprayed with sterile tap water.

The center of each cotyledon was punctured by a needle, and a 3-mm mycelial plug from the edge of an actively growing 3-day-old culture on PDA was placed on the wound. Six plants (12 cotyledons) were inoculated per isolate and fungicide treatment. The inoculated plants were transferred to a moisture chamber at $23^{\circ} \mathrm{C}$ for 4 days. After this period of incubation, diseased plants were removed from the moisture chamber and the infection was recorded by evaluating the lesion on each cotyledon. The evaluation was carried out by using a disease-index scale suggested by Ziogas et al. (33) as follows: 0, no infection; 0.5, rot only under the inoculum; 1, less than $20 \%$ rot; 2,21 to $50 \%$ rot; and 4 , rot on more than $50 \%$ of the cotyledon surface. The experiment was replicated twice.

Data analysis. Values of disease severity on inoculated cucumber cotyledons were subjected to analysis of variance, and means were compared by Duncan's multiple range test. Because data from the two replications did not differ significantly $(P$ $>0.05)$, the mean disease severity values from the two experiments for each isolate and treatment were used in the data analysis. The $\mathrm{EC}_{50}$ values (effective concentration that reduces mycelial growth or spore germination by $50 \%$ ) of each isolate to boscalid and pyraclostrobin were calculated by regressing the relative inhibition of growth or spore germination against the $\log _{10}$ fungicide concentration using JMP (JMP, SAS Institute, Cary, NC). The mean value of the three replicate tests per isolate and concentration were used to calculate the $\mathrm{EC}_{50}$ values. To measure crossresistance between pairs of fungicides, the $\mathrm{EC}_{50}$ values were correlated and the correlation coefficients $(r)$ were calculated. The $\mathrm{EC}_{50}$ values were transformed to $\log _{10}$ values before analysis.

\section{RESULTS}

Baseline sensitivity to boscalid and pyraclostrobin. A total of 55 single-spore

Table 1. Level of sensitivity to several fungicides (in terms of $\mathrm{EC}_{50}$ values) of Botrytis cinerea isolates used in the study

\begin{tabular}{|c|c|c|c|c|c|c|}
\hline \multirow[b]{2}{*}{ Isolates } & \multirow[b]{2}{*}{ Host of origin } & \multirow[b]{2}{*}{ Characterization $^{\mathrm{z}}$} & \multicolumn{4}{|c|}{$\mathrm{EC}_{50}\left(\mu \mathrm{g} \mathrm{ml}^{-1}\right)^{\mathrm{y}}$} \\
\hline & & & Carbendazim & Cyprodinil & Pyraclostrobin & Boscalid \\
\hline $13 \mathrm{~g}$ & Tomato & BENR & $>100$ & 0.004 & 0.042 & 3.55 \\
\hline $15 \mathrm{~d}$ & Tomato & BENR & $>100$ & 0.003 & 0.072 & 1.17 \\
\hline $1 d$ & Eggplant & ANIR & 0.08 & 5.0 & 0.022 & 1.65 \\
\hline $7 \mathrm{e}$ & Eggplant & ANIR & 0.05 & 10.0 & 0.020 & 2.40 \\
\hline $16 \mathrm{e}$ & Tomato & WTBC & 0.10 & 0.004 & 0.025 & 4.35 \\
\hline 6 & Tomato & WTBC & 0.07 & 0.004 & 0.025 & 3.30 \\
\hline
\end{tabular}

${ }^{\mathrm{y}}$ Measurement of effective concentration values that reduce mycelial growth or spore germination by $50 \%\left(\mathrm{EC}_{50}\right)$ was based on mycelial growth test for carbendazim, cyprodinil, and boscalid and on spore germination test for pyraclostrobin.

${ }^{\text {z }}$ BENR: benzimidazole-resistant isolates; ANIR: anilinopyrimidine-resistant isolates; WTBC: wild-type sensitivity B. cinerea isolate. 
isolates of $B$. cinerea were tested for sensitivity to boscalid on the basis of mycelial growth and spore germination and to pyraclostrobin on the basis of spore germination. For both pyraclostrobin and boscalid, the frequency distribution of the $\mathrm{EC}_{50}$ values was a unimodal curve (Figs. 1 and 2). The $\mathrm{EC}_{50}$ values for each fungicide are shown in Table 2. The individual $\mathrm{EC}_{50}$ values for pyraclostrobin ranged from 0.005 to $0.077 \mu \mathrm{g} \mathrm{ml}^{-1}$ and thus were separated by a factor of 15 , while the mean $\mathrm{EC}_{50}$ had a value of $0.033 \mu \mathrm{g} \mathrm{ml} \mathrm{m}^{-1}$. The intrinsic activity of boscalid was lower compared with that of pyraclostrobin. The individual $\mathrm{EC}_{50}$ values for boscalid, when sensitivity was measured based on inhibition of spore germination, ranged from 0.09 to $5.60 \mu \mathrm{g} \mathrm{ml}^{-1}$ with a mean value of $2.14 \mu \mathrm{g} \mathrm{ml}^{-1}$, while the sensitivity measured on the basis of mycelial growth ranged from 0.075 to $5.05 \mu \mathrm{g} \mathrm{ml}^{-1}$ with a mean value of $2.09 \mu \mathrm{g} \mathrm{ml}^{-1}$. In the first case, the individual $\mathrm{EC}_{50}$ values were separated by a factor of 62 , while in the second they were separated by a factor of 67 (Table 2).

Cross-resistance relationships. The sensitivity to boscalid was plotted versus the sensitivity to pyraclostrobin, and the log-transformed $\mathrm{EC}_{50}$ values were analyzed by establishing correlation and linear regression. In addition, the sensitivity to these two fungicides was plotted versus the sensitivity to cyprodinil, pyrimethanil, fludioxonil, fenhexamid, and iprodione, which had been determined for the same isolates in a previous study (21). Correlation coefficients between all the fungicide pairs are presented in Table 3. For all combinations, the correlation coefficients were very low, ranging from 0.03 to 0.19 , and none were significant $(P>0.05)$.

Control of anilinopyrimidine- and benzimidazole-resistant strains. Data on disease severity and control efficacy obtained by the several treatments are summarized in Table 4. Specifically, applications of both pyraclostrobin and boscalid at the higher concentrations of 50 and $100 \mu \mathrm{g}$ $\mathrm{ml}^{-1}$ significantly suppressed the disease caused by all isolates compared with the control treatments $(P<0.05)$, and the control efficacy had values higher than $90 \%$. In contrast, cyprodinil failed to control satisfactorily the anilinopyrimidineresistant strains. Disease severity on the plants treated with cyprodinil, either at 50 or $100 \mu \mathrm{g} \mathrm{ml}^{-1}$, and inoculated with anilinopyrimidine-resistant isolates was significantly higher $(P<0.05)$ compared with the disease severity on plants treated with either boscalid or pyraclostrobin. Similarly, applications of carbendazim at 100 $\mu \mathrm{g} \mathrm{ml}{ }^{-1}$ failed to suppress satisfactorily the disease caused by the benzimidazoleresistant strains, while they efficiently controlled the anilinopyrimidine-resistant isolates and the isolates of wild-type sensitivity. Disease severity on cucumber seed- lings treated with carbendazim and inoculated with benzimidazole-resistant strains was significantly higher $(P<0.05)$ compared with that observed on pyraclostrobin- or boscalid-treated plants, but lower $(P<0.05)$ than that observed on the untreated control plants.

\section{DISCUSSION}

Emergence of resistance to botryticides such as the benzimidazole, dicarboximide, and anilinopyrimidine fungicides has become a limitation to the sustained control of gray mold caused by $B$. cinerea on vegetable crops and grapevines worldwide. The development of new fungicide compounds with good efficacy against the disease and novel biochemical mechanisms of action, and their introduction into the spray programs applied against gray mold, is a prerequisite for successful disease management, particularly in crops

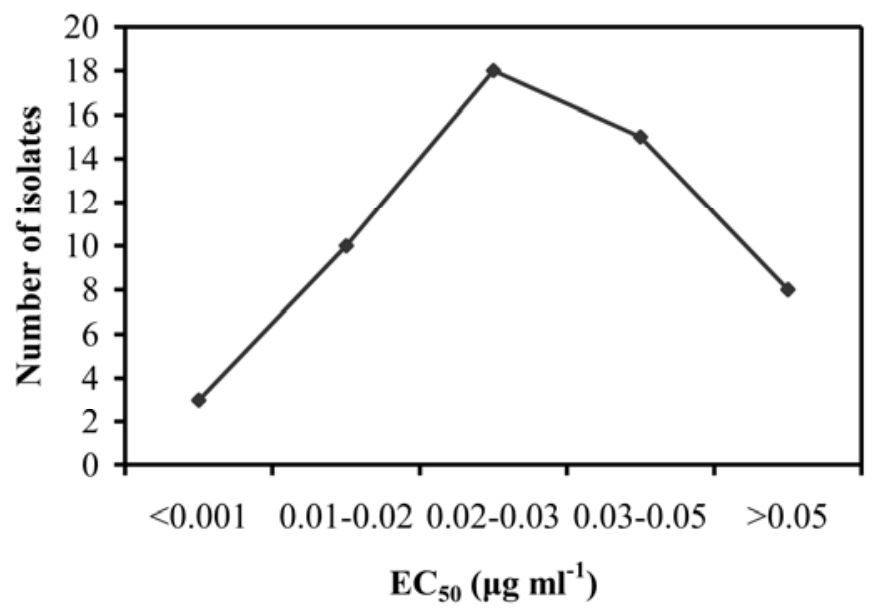

Fig. 1. Baseline sensitivity of Botrytis cinerea isolates to pyraclostrobin based on inhibition of spore germination. $\mathrm{EC}_{50}=$ effective concentration that reduces mycelial growth or spore germination by $50 \%$.
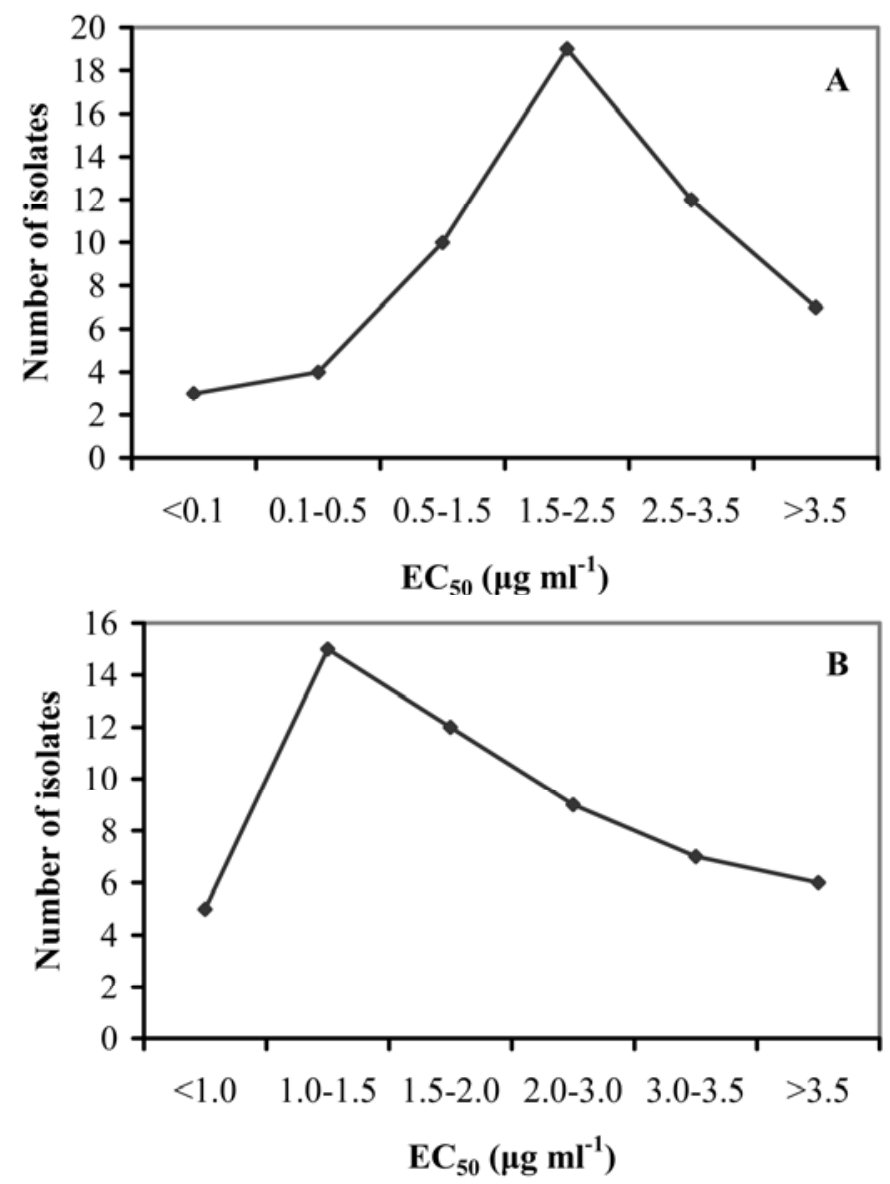

Fig. 2. Baseline sensitivity of Botrytis cinerea isolates to boscalid based on the inhibition of $\mathbf{A}$, spore germination, and $\mathbf{B}$, mycelial growth $\mathrm{EC}_{50}=$ effective concentration that reduces mycelial growth or spore germination by $50 \%$. 
with high disease pressure and where problems of resistance to site-specific fungicides have emerged.

In the current study, the baseline sensitivity of $B$. cinerea to two novel compounds was established using isolates collected from vegetable crops grown in greenhouses on Crete island, Greece. The isolates were collected during the winter period of 2005 before the introduction of boscalid and pyraclostrobin into the spray programs applied against the disease. The number of isolates used in this study fell within the limits provided by Russel (27), who suggests that 50 isolates will likely give a reasonable picture of the baseline sensitivity of a fungal population. Establishment of baseline sensitivity data is of great importance in fungicide resistance management, since they can be used to illustrate shifts in pathogen sensitivity and provide evidence that control failures occurring in the future can be correlated with the appearance of resistance in the population $(12,27)$. Determination of the isolates' sensitivity to pyraclostrobin was based on the inhibition of spore germination, since strobilurin fungicides show a dominant effect on this developmental stage $(5,25,31)$. Sensitivity distribution to pyraclostrobin was unimodal with a relatively narrow sensitivity range. A similar narrow baseline sensitivity range to strobilurin fungicides has been observed in several other pathogens $(10,22,30)$. To the best of our knowledge, this is the first report of the baseline sensitivity of $B$. cinerea isolates to pyraclostrobin.

Sensitivity to boscalid was determined based both on inhibition of spore germination and mycelial growth since it is known that in addition to being a strong inhibitor of spore germination, this fungicide is also very effective against all other major stages of fungal growth (28). In both cases, the sensitivity distribution to boscalid was

Table 2. Baseline sensitivity of Botrytis cinerea isolates, obtained from vegetable crops, to boscalid and pyraclostrobin

\begin{tabular}{llccc}
\hline & & \multicolumn{2}{c}{$\mathbf{E C}_{\mathbf{5 0}}\left(\boldsymbol{\mu g} \mathbf{~ m l}^{\mathbf{- 1}}\right)$} & \\
\cline { 3 - 4 } Fungicide & Stage of inhibition & Range & Mean & VF $^{\mathbf{z}}$ \\
\hline Pyraclostrobin & Spore germination & $0.005-0.077$ & 0.033 & 15 \\
Boscalid & Mycelial growth & $0.075-5.050$ & 2.09 & 67 \\
Boscalid & Spore germination & $0.090-5.600$ & 2.14 & 62 \\
\hline
\end{tabular}

${ }_{\mathrm{z}}$ Variation factor $=$ highest $\mathrm{EC}_{50}$ value (effective concentration that reduces mycelial growth or spore germination by $50 \%$ ) divided by the lowest $\mathrm{EC}_{50}$ value.

Table 3. Cross-resistance patterns between pyraclostrobin, boscalid, cyprodinil, pyrimethanil, fludioxonil, fenhexamid, and iprodione in Botrytis cinerea isolates obtained from vegetable crops

\begin{tabular}{llllll}
\hline & \multicolumn{2}{c}{ Pyraclostrobin } & & \multicolumn{2}{c}{ Boscalid } \\
\cline { 2 - 3 } \cline { 5 - 6 } Fungicide & $\boldsymbol{r}^{\mathbf{y}}$ & $\boldsymbol{P}^{\mathbf{z}}$ & & $\boldsymbol{r}$ & $\boldsymbol{P}$ \\
\hline Boscalid & 0.09 & 0.47 & & - & - \\
Cyprodinil & 0.001 & 0.98 & & 0.12 & 0.35 \\
Pyrimethanil & 0.03 & 0.81 & & 0.11 & 0.41 \\
Fludioxonil & 0.05 & 0.68 & & 0.19 & 0.16 \\
Fenhexamid & 0.13 & 0.33 & & 0.08 & 0.54 \\
Iprodione & 0.04 & 0.73 & & 0.08 & 0.55 \\
\hline
\end{tabular}

${ }^{\text {y }} r=$ correlation coefficient value.

${ }^{\mathrm{z}}$ Correlation coefficients are significant at $P<0.05$.

unimodal and similar to that observed for pyraclostrobin. The baseline sensitivity distribution that we obtained, based on the inhibition of mycelial growth, appears to be consistent with a previously reported range of $\mathrm{EC}_{50}$ values of 0.09 to $3.69 \mu \mathrm{g} \mathrm{ml}^{-1}$ (32). These values are higher than those provided by Stammler and Speakman (29), but this is probably due to differences in the experimental approach for the $\mathrm{EC}_{50}$ measurement. In their study, Stammler and Speakman (29) determined $\mathrm{EC}_{50}$ values based on a microtiter method combining the inhibition of both spore germination and mycelial growth; the growth substrate was also different. The level of sensitivity to boscalid, in terms of $\mathrm{EC}_{50}$ values, based on the inhibition of spore germination for most of the isolates tested, was similar to that based on the inhibition of mycelial growth. However, it should be mentioned that in the current study, mycelial growth for most isolates was not completely inhibited even at the higher concentration of $5 \mu \mathrm{g} \mathrm{ml}^{-1}$. This is in accordance with the findings presented by Zhang et al. (32), who reported higher levels of sensitivity of $B$. cinerea to boscalid based on the inhibition of spore germination compared with that based on the inhibition of mycelial growth. However, in a recent report regarding the sensitivity of Alternaria alternata isolates from pistachio to boscalid, it was found that mycelial growth in that fungal species was more sensitive than spore germination for evaluating the inhibitory effects of boscalid against the pathogen (3).

Regarding the cross-sensitivity relationship between pyraclostrobin and boscalid, the results of the current study showed that there was no correlation between the sensitivity to these two fungicides. A similar conclusion was obtained in a recent study of cross-resistance relationships with pyraclostrobin-resistant isolates of $A$. alternata from pistachio (3). In contrast, two previous reports suggested that strobilurinresistant strains of Alternaria solani and $B$. cinerea were more sensitive to boscalid

Table 4. Disease severity and control efficacy (\%) of gray mold caused by Botrytis cinerea isolates with different levels of sensitivity to fungicides on cucumber seedlings treated with cyprodinil, carbendazim, boscalid, and pyraclostrobin

\begin{tabular}{|c|c|c|c|c|c|c|c|c|c|c|c|c|c|}
\hline \multirow[b]{3}{*}{ Treatment } & \multirow[b]{3}{*}{ Dose $^{w}$} & \multicolumn{4}{|c|}{ Benzimidazole-resistant isolates } & \multicolumn{4}{|c|}{ Anilinopyrimidine-resistant isolates } & \multicolumn{4}{|c|}{ Wild-type sensitivity isolates } \\
\hline & & \multicolumn{2}{|c|}{ 15D } & \multicolumn{2}{|c|}{ 13G } & \multicolumn{2}{|c|}{ 1D } & \multicolumn{2}{|c|}{$7 \mathbf{E}$} & \multicolumn{2}{|c|}{$16 E$} & \multicolumn{2}{|c|}{6} \\
\hline & & $\mathbf{D S}^{\mathbf{x}}$ & $\mathbf{C E}^{\mathbf{y}}$ & DS & CE & DS & $\mathbf{C E}$ & DS & $\mathbf{C E}$ & DS & $\mathbf{C E}$ & DS & $\mathbf{C E}$ \\
\hline Cyprodinil & 50 & $0.78 \mathrm{c}^{\mathrm{z}}$ & 81 & $0.87 \mathrm{c}$ & 78 & $2.37 \mathrm{e}$ & 41 & $3.00 \mathrm{~d}$ & 25 & $0.12 \mathrm{a}$ & 97 & $0.43 \mathrm{~d}$ & 89 \\
\hline Cyprodinil & 100 & $0.40 \mathrm{~b}$ & 90 & $0.43 \mathrm{~b}$ & 89 & $1.59 \mathrm{~d}$ & 60 & $1.75 \mathrm{c}$ & 56 & $0.15 \mathrm{a}$ & 96 & $0.12 \mathrm{a}$ & 97 \\
\hline Carbendazim & 100 & $3.00 \mathrm{~d}$ & 25 & $2.93 \mathrm{~d}$ & 27 & $0.59 \mathrm{bc}$ & 85 & $0.21 \mathrm{a}$ & 95 & $0.37 \mathrm{~b}$ & 91 & $0.34 \mathrm{~b}-\mathrm{d}$ & 92 \\
\hline Pyraclostrobin & 25 & $0.50 \mathrm{~b}$ & 88 & $0.37 \mathrm{ab}$ & 91 & $0.84 \mathrm{c}$ & 79 & $0.40 \mathrm{ab}$ & 90 & $0.25 \mathrm{ab}$ & 94 & $0.25 \mathrm{a}-\mathrm{d}$ & 94 \\
\hline Pyraclostrobin & 50 & $0.25 \mathrm{ab}$ & 94 & $0.31 \mathrm{ab}$ & 92 & $0.59 \mathrm{bc}$ & 85 & $0.25 \mathrm{ab}$ & 94 & $0.12 \mathrm{a}$ & 97 & $0.21 \mathrm{a}-\mathrm{c}$ & 95 \\
\hline Pyraclostrobin & 100 & $0.12 \mathrm{a}$ & 97 & $0.21 \mathrm{ab}$ & 95 & $0.40 \mathrm{ab}$ & 90 & $0.18 \mathrm{a}$ & 96 & $0.12 \mathrm{a}$ & 97 & $0.15 \mathrm{ab}$ & 96 \\
\hline Boscalid & 25 & $0.50 \mathrm{~b}$ & 88 & $0.87 \mathrm{c}$ & 78 & $0.90 \mathrm{c}$ & 69 & $0.53 \mathrm{~b}$ & 87 & $0.37 \mathrm{~b}$ & 91 & $0.37 \mathrm{~cd}$ & 91 \\
\hline Boscalid & 50 & $0.21 \mathrm{ab}$ & 95 & $0.25 \mathrm{ab}$ & 94 & $0.37 \mathrm{ab}$ & 91 & $0.34 \mathrm{ab}$ & 92 & $0.25 \mathrm{ab}$ & 94 & $0.09 \mathrm{a}$ & 98 \\
\hline Boscalid & 100 & $0.06 \mathrm{a}$ & 99 & $0.15 \mathrm{a}$ & 96 & $0.12 \mathrm{a}$ & 97 & $0.28 \mathrm{ab}$ & 93 & $0.15 \mathrm{a}$ & 96 & $0.15 \mathrm{ab}$ & 96 \\
\hline Control & & $4.00 \mathrm{e}$ & - & $4.00 \mathrm{e}$ & - & $4.00 \mathrm{f}$ & - & $4.00 \mathrm{e}$ & - & $4.00 \mathrm{c}$ & - & $4.00 \mathrm{e}$ & - \\
\hline
\end{tabular}

${ }^{\mathrm{w}} \mu \mathrm{g}$ a.i. $\mathrm{ml}^{-1}$.

${ }^{x}$ DS: disease severity. Measurements of disease severity were based on a disease scale from 1 to 5 as suggested by Ziogas et al. (33).

y CE: control efficacy. Percent control efficacy values were calculated as $100-$ disease severity (treated) / disease severity (untreated) $\times 100$.

${ }^{z}$ Means followed by different letters in a column are significantly different according to Duncan's multiple range test at $P=0.05$. 
than the strobilurin-sensitive strains of these pathogens $(17,24)$. However, the data presented in our study were derived using baseline isolates that had never been exposed to the fungicides tested, and there was no resistance to either of the two fungicides. In addition, we found no correlation of sensitivities between sensitivity to boscalid or pyraclostrobin and sensitivity to cyprodinil, pyrimethanil, fenhexamid, fludioxonil, and iprodione. In a recent study carried out using isolates of $B$. cinerea with laboratory-induced resistance to pyraclostrobin, a negative cross-resistance relationship between pyraclostrobin and cyprodinil was observed, while there was no correlation between the level of sensitivity to pyraclostrobin and the level of sensitivity to fenhexamid or to fludioxonil (17).

In this study, the control efficacy provided by boscalid and pyraclostrobin also was investigated. The results showed that boscalid and pyraclostrobin can successfully control anilinopyrimidine- and benzimidazole-resistant strains of $B$. cinerea. Under controlled environmental conditions, applications of both boscalid and pyraclostrobin, even at the lowest concentration tested of $25 \mu \mathrm{g} \mathrm{ml}^{-1}$, provided satisfactory control of the disease on plants inoculated with either the benzimidazoleresistant (BENR) or the anilinopyrimidineresistant (ANIR) isolates of the pathogen. At the same time, cyprodinil and carbendazim failed to protect satisfactorily plants inoculated with the ANIR and the BENR isolates, respectively.

Such results suggest that both boscalid and pyraclostrobin could play a key role in gray mold management in the near future and encourage their introduction into the spray programs. However, the highly specific mode of action indicates a high risk for rapid selection of resistant genotypes among pathogen populations. Field resistance to strobilurin fungicides has been developed in several pathogens more rapidly than expected $(11,14,16)$, while resistance to boscalid has been observed in field isolates of A. alternata from pistachio $(2,3)$. This potentially high risk for resistance development suggests the need for strategies to reduce the risk. Consequently, further research is required to design the most effective fungicide spray schedules and to select the most effective partners for use in mixtures.

\section{ACKNOWLEDGMENTS}

We thank BASF Hellas S.A. for providing pure technical grades and the commercial formulations of pyraclostrobin and boscalid.

\section{LITERATURE CITED}

1. Ammermann, E., Lorenz, G., Schelberger, K., Mueller, B., Kirstgen, R., and Sauter, H. 2000.
BAS $500 \mathrm{~F}$ - The new broad-spectrum strobilurin fungicide. Pages 541-548 in: Proc. BCPC Conf. Pests Dis. BCPC, Farnham, Surrey, UK.

2. Avenot, H. F., and Michailides, T. J. 2007. Resistance to boscalid fungicide in Alternaria alternata isolates from pistachio in California. Plant Dis. 91:1345-1350.

3. Avenot, H., Morgan, D. P., and Michailides, T. J. 2008. Resistance to pyraclostrobin, boscalid and multiple resistance to Pristine ${ }^{\circledR}$ (pyraclostrobin + boscalid) fungicide in Alternaria alternata causing Alternaria late blight of pistachios in California. Plant Pathol. 57:135-140.

4. Baroffio, C. A., Siegfried, W., and Hilber, U. W. 2003. Long-term monitoring for resistance of Botryotinia fuckeliana to anilinopyrimidine, phenylpyrrole, and hydroxyanilide fungicides in Switzerland. Plant Dis. 87:662-666.

5. Bartlett, D. W., Clough, J. M., Godwin, J. R., Hall, A. A., Hamer, M., and Parr-Dobrzanski, B. 2002. The strobilurin fungicides. Pest Manag. Sci. 58:649-662.

6. Broomfield, P. L. E., and Hargreaves, J. A. 1992. A single-amino acid change in the ironsulphur protein subunit of succinate dehydrogenase confers resistance to carboxin in Ustilago maydis. Curr. Genet. 22:117-121.

7. Elad, Y., Gullino, M. L., Shtienberg, D., and Aloi, C. 1995. Managing Botrytis cinerea on tomatoes in greenhouses in the Mediterranean. Crop Prot. 14:105-109.

8. Elad, Y., Yunis, H., and Katan, T. 1992. Multiple resistance to benzimidazoles, dicarboximides and diethofencarb in field isolates of Botrytis cinerea in Israel. Plant Pathol. 41:4146.

9. Fraile, A., Alonso, A., and Sagasta, E. M. 1986. Some characteristics of Botrytis cinerea isolates tolerant to procymidone. Plant Pathol. 35:82-85.

10. Gisi, U., Hermann, D., Ohl, L., and Steden, C. 1997. Sensitivity profiles of Mycosphaerella graminicola and Phytophthora infestans populations to different classes of fungicides. Pestic. Sci. 51:290-298.

11. Ishii, H., Fraaije, B. A., Sugiyama, T., Noguchi, K., Nishimura, K., Takeda, T., Amano, T., and Hollomon, D. W. 2001. Occurrence and molecular characterization of strobilurin resistance in cucumber powdery mildew and downy mildew. Phytopathology 91:1166-1171.

12. Justum, A. R., Heany, S. P., Perrin, B. M., and Wege, P. J. 1998. Pesticide resistance: Assessment of risk and implementation of effective management strategies. Pestic. Sci. 54:435446.

13. Karadimos, D. A., Karaoglanidis, G. S., and Tzavella-Klnari, K. 2005. Biological activity and physical modes of action of the $\mathrm{Q}_{0}$ inhibitor fungicides trifloxystrobin and pyraclostrobin against Cercospora beticola with strobilurin fungicides. Crop Prot. 24:23-29.

14. Köller, W., Parker, D. M., Turechek, W. W., Avila-Adame, C., and Cronshaw, K. 2004. A two-phase resistance response of Venturia inaequalis populations to the QoI fungicides kresoxim-methyl and trifloxystrobin. Plant Dis. 88:537-544.

15. Leroux, P., Chapeland, F., Desbrosses, D., and Gredt, M. 1999. Patterns of cross-resistance to fungicides in Botryotinia fuckeliana (Botrytis cinerea) isolates from French vineyards. Crop Prot. 18:687-697.

16. Ma, Z., Felts, D., and Michailides, T. J. 2003. Resistance to azoxystrobin in Alternaria isolates from pistachio in California. Pestic. Biochem. Physiol. 77:66-74.
17. Markoglou, A. N., Malandrakis, A. A., Vitoratos, A. G., and Ziogas, B. N. 2006. Characterization of laboratory mutants of Botrytis cinerea resistant to $\mathrm{Q}_{\mathrm{O}} \mathrm{I}$ fungicides. Eur. J. Plant Pathol. 115:149-162.

18. Matheron, M. E., and Porchas, M. 2004. Activity of boscalid, fenhexamid, fluazinam, fludioxonil, and vinclozolin on growth of Sclerotinia minor and $S$. sclerotiorum and development of lettuce drop. Plant Dis. 88:665-668.

19. Moorman, G. W., and Lease, R. J. 1992. Benzimidazole and dicarboximide-resistant Botrytis cinerea from Pennsylvania greenhouse. Plant Dis. 76:477-480.

20. Moyano, C., Gomez, V., and Melgarejo, P. 2004. Resistance to pyrimethanil and other fungicides in Botrytis cinerea populations collected on vegetable crops in Spain. J. Phytopathol. 152:484-490.

21. Myresiotis, C. K., Karaoglanidis, G. S., and Tzavella-Klonari, K. 2007. Resistance of Botrytis cinerea isolates from vegetable crops to anilinopyrimidine, phenylpyrrole, hydroxyanilide, benzimidazole, and dicarboximide fungicides. Plant Dis. 91:407-413.

22. Olaya, G., and Köller, W. 1999. Diversity of kresoxim-methyl sensitivities in baseline populations of Venturia inaequalis. Pestic. Sci. 55:1083-1088.

23. Pappas, A. C. 1997. Evolution of fungicide resistance in Botrytis cinerea in protected crops in Greece. Crop Prot. 16:257-263.

24. Pasche, J. S., Piche, L. M., and Gudmestad, N. C. 2005. Effect of the F129L mutation in Alternaria solani on fungicides affecting mitochondrial respiration. Plant Dis. 89:269278.

25. Pasche, J. S., Wharam, C. M., and Gudmestad, N. C. 2004. Shift in sensitivity of Alternaria solani in response to $\mathrm{Q}_{\mathrm{o}} \mathrm{I}$ fungicides. Plant Dis. 88:181-187.

26. Rosslenbroich, H. J., and Stuebler, D. 2000. Botrytis cinerea - History of chemical control and novel fungicides for its management. Crop Prot. 19:557-561.

27. Russel, P. E. 2004. Sensitivity baselines in fungicide resistance research and management. FRAC, Monogr. No. 3, Brussels

28. Stammler, G., Brix, H. D., Nave, B., Gold, R., and Schoefl, U. 2007. Studies on the biological performance of boscalid and its mode of action. (Abstr.) Int. Reinhardsbrunn Sympos. 15th. Modern fungicides and antifungal compounds. Friedrichroda, Germany.

29. Stammler, G., and Speakman, J. 2006. A microtiter method to test the sensitivity of Botrytis cinerea to boscalid. J. Phytopathol 154:508-510

30. Wong, F. P., and Wilcox, W. F. 2000. Distribution of baseline sensitivities to azoxystrobin among isolates of Plasmopara viticola. Plant Dis. 84:275-281.

31. Ypema, H. L., and Gold, R. E. 1999. Kresoxim-methyl: Modification of a naturally occurring compound to produce a new fungicide. Plant Dis. 83:4-19.

32. Zhang, C. Q., Yuan, S. K., Sun, H. Y., Qi, Z. Q., Zhou, M. G., and Zhu, G. N. 2007. Sensitivity of Botrytis cinerea from vegetable greenhouses to boscalid. Plant Pathol. 56:646653.

33. Ziogas, B. N., Markoglou, A. N., and Spyropoulou, V. 2005. Effect of phenylpyrroleresistance mutations on ecological fitness of Botrytis cinerea and their genetical basis in Ustilago maydis. Eur. J. Plant Pathol. 113:83100. 